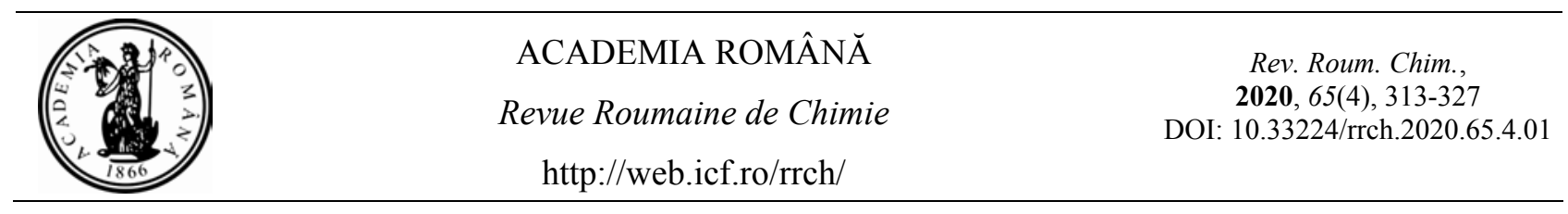

Review

\title{
APPLICATION OF OXIDATION PROCESSES IN THE PURIFICATION OF WASTEWATERS FROM PHENOLIC COMPOUNDS
}

\author{
Milica MATIJEVIĆ, ${ }^{\mathrm{a}}$ Maja N. STANKOVIĆ, ${ }^{\mathrm{b}}$ Nenad S. KRSTIĆ, ${ }^{\mathrm{b}}$ \\ Milica G. NIKOLIĆ ${ }^{b}$ and Danijela A. KOSTIĆb,**
}

\footnotetext{
${ }^{a}$ Vinca Institute of Nucelar Sciences, University of Belgrade, Mike Petrovića Alasa 12-14, 11000 Belgrade, Serbia ${ }^{b}$ University of Niš, Department of Chemistry, Faculty of Sciences and Mathematics, Višegradska 33, 18000 Niš, Serbia
}

Natural phenolic compounds are significant component of the human diet, as they are present in fruits and vegetables, and they have very important biological activity in the living organisms. Because of their structure, they are subject of numerous oxidation processes, such as autoxidation, but are easily to oxidize in presence of various oxidizing agents and enzymes. Many authors have been investigating phenolic oxidation processes, and have successfully identified their pathways and a significant number of intermediates and products generated by these processes. Also, particular attention has been made to the effects of these processes on food quality and other biological processes in living organisms. Phenols are persistent pollutants of water systems from various agricultural activities and industrial wastewater discharges. It is known that the presence of phenolic compounds in water supplies and industrial effluents directly affects natural processes in the environment due to their toxicity and natural ability to decompose. This property, to easily oxidize and, as a result of it, to mineralize, is practically useful for the treatment of the wastewaters, so it is of global

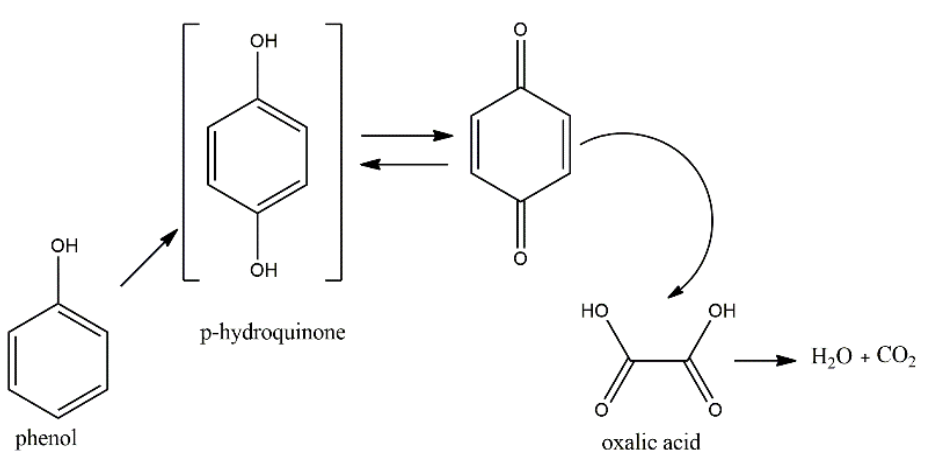
concern to manage the best technology to remove phenols and other organic pollutants, assisted with the oxidation processes. In the aspect of treatment of wastewaters polluted with phenols, we reviewed oxidative processes such as autoxidation, enzyme-catalyzed oxidation, photo-oxidation, electrochemical oxidation and oxidation by Fenton's reagent and, based on the literature data, we presented advantages and disadvantages of these processes compared to each other.

\section{INTRODUCTION}

\section{Phenolic compounds}

Phenolic compounds have important physiological roles in plants oxidation processes, and the most important one is to protect plants against various biotic and abiotic stresses. These processes also have an impact to the quality of human diet as browning of plant-derived foods and beverages is a consequence of oxidation of the phenolic compounds in plant tissue. As some of them absorb in the visible range, phenolic compounds are pigments of yellow,

\footnotetext{
* Corresponding author: danijelaaakostic@yahoo.com
} 
orange, red, and blue color of different plant organs. In foods, they are responsible for the major organoleptic characteristics like taste, texture, and appearance. Phenols are grouped into simple phenols (e.g., phenolic acids and hydroxycinnamic acids) and polyphenols (flavonoids and proanthocyanidins). ${ }^{1}$ The major biological role is associated with the group of the flavonoids, as they are attributed to potential cytotoxicity and antioxidant abilities. ${ }^{2}$ Radicalscavenging capacity is involved in antioxidant properties, which prevents many diseases, mainly cardiovascular and some forms of cancer. ${ }^{3}$

The phenols, as other aliphatic alcohols, have the hydroxyl group attached to an atom of carbon, but this phenolic hydroxyl group is more labile as it is influenced by the aromatic ring, so phenols act as weak acids. Polyphenols are highly reactive compounds as they have more than one hydroxyl group, which is attached to one or more benzene rings, so they undergo numerous enzymatic and chemical reactions, such are the reaction of oxidation.

\section{Oxidative processes of phenolic compounds}

Phenolic compounds participate in numerous oxidative processes. Both pathways of synthesis of phenols and oxidative processes involved are shown at Figure 1. These processes can be autoxidative or helped with enzymes, radiation, radiation catalysed with semiconductor, electric current, and different chemical agents in different environments, as we review them in separated chapters.

While the flavonoid oxidation in plant seeds and other parts of a plant in development, is mainly catalysed by enzymes in the manner that polyphenol oxidases are responsive for browning of plant tissue and peroxidases, in other environments, such are fauna and water systems, many different oxidative processes of phenols can occur. ${ }^{2}$

The ability to easily oxidize and, on the end, to mineralize, oxidative processes have been used for wastewater treatment to remove phenols and other organic pollutants. Chemical oxidation reactions involving hydroxyl radicals have been extremely effective in this aspect. These oxidative processes are known as advanced chemical oxidation processes (AOP). The AOP use stronger oxidant than oxygen, like ozone and hydroxyl radicals, generated by the combination of oxidation agents (such as $\mathrm{H}_{2} \mathrm{O}_{2}, \mathrm{O}_{3}$, Fenton reagent), irradiation (such as UV or ultrasound), and catalysts (such as metal ions or photocatalysts), or electrochemistry at a convenient potential. ${ }^{4}$ However, hydroxyl radicals $(\mathrm{OH} \bullet)$ are more powerful oxidant $\left(\mathrm{E}^{\circ} 2.8 \mathrm{~V}\right)$ than ozone $\left(\mathrm{E}^{\circ} 2.0 \mathrm{~V}\right)$ or $\mathrm{H}_{2} \mathrm{O}_{2}\left(\mathrm{E}^{\circ} 1.8 \mathrm{~V}\right)$ that makes it the strongest inorganic oxidant next to elemental fluorine. ${ }^{5}$ The hydroxyl radical is also stable over a wide $\mathrm{pH}$ range,up to $\mathrm{pH} 10$, and its mechanisms of oxidation are well known as hydroxyl addition, hydrogen abstraction, and electron transfer. ${ }^{4}$

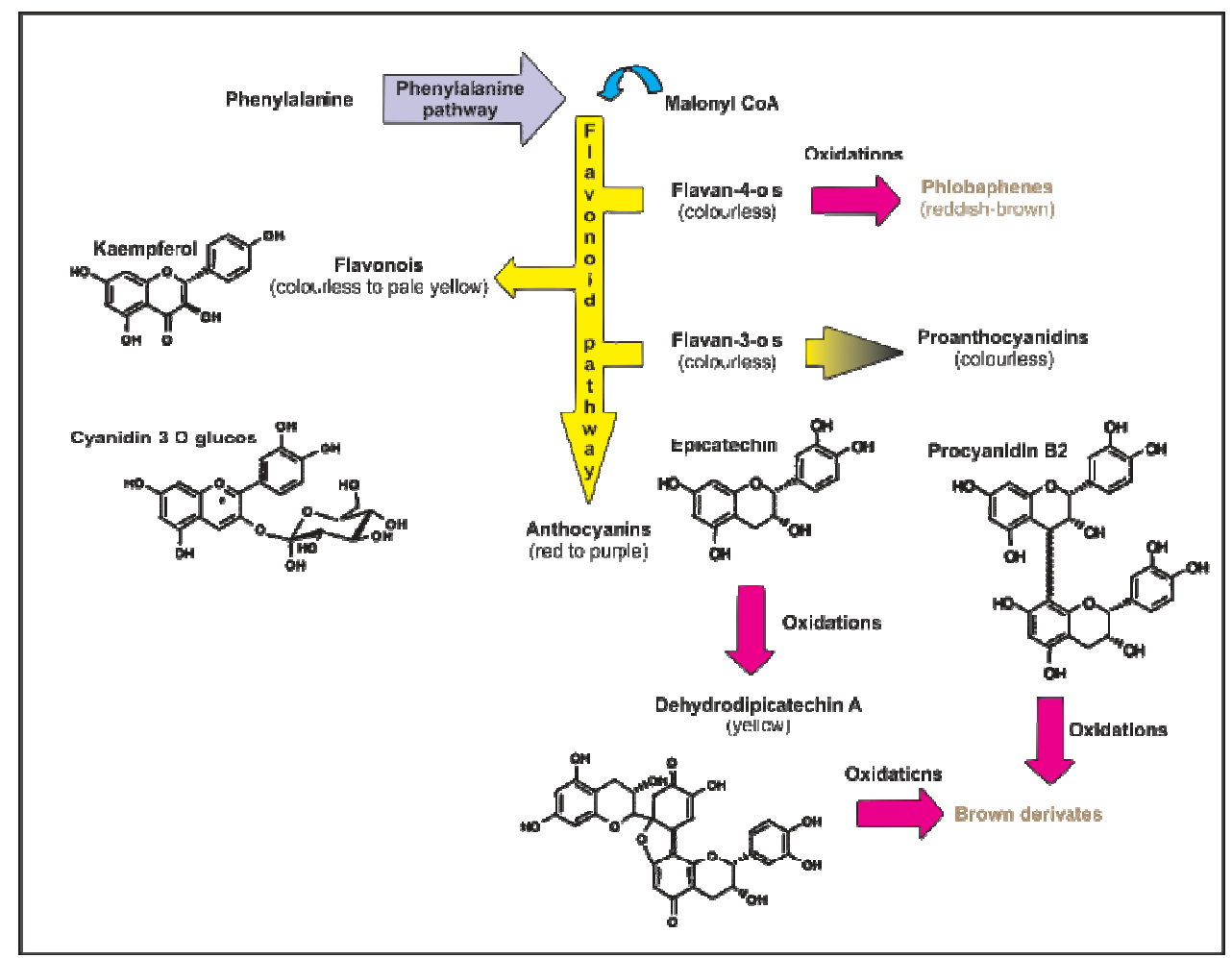

Fig. 1 - Biosynthesis and oxidation path of the main classes of flavonoids. 


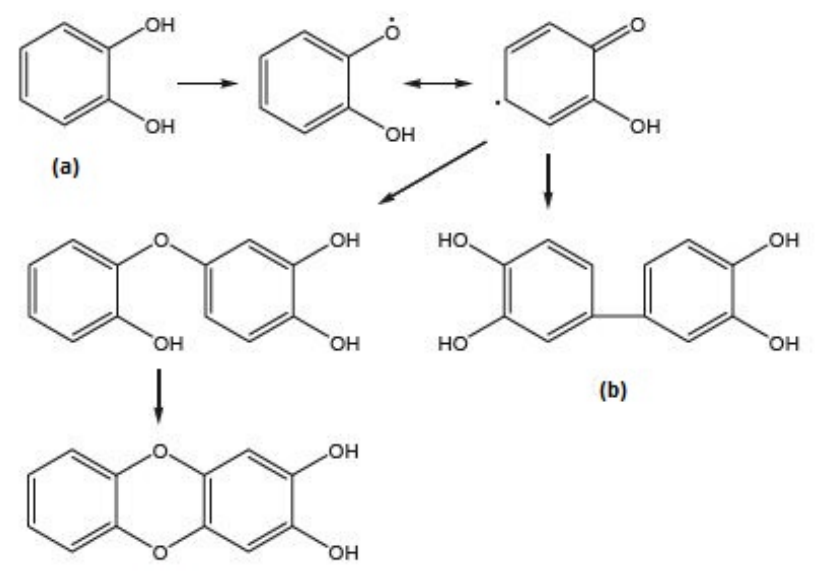

(c)

Fig. 2 - Catechol (a) and possible products of autoxidation by the authors Vermerris and Nicholson: (b) tetrahydroxy-biphenyl and (c) quinine.

The example of this studies was performed by Talcott and Howard. They had monitored the changes in color due to autoxidation of carrot puree and total soluble phenolics concentration during storage. Strained carrots were thermally processed with reduced oxygen pretreatments with different agents, or without any in control group, and later all together were exposed to temperatures of $40^{\circ} \mathrm{C}$ for four weeks, in order to simulate storage conditions. The greatest loss of color was observed in the control group as the consequence of phenolic polymerization due to autoxidation, so the processed pretreatments have shown that the quality of the puree could be retained, and autoxidation could be prevented. ${ }^{7}$

As the process of autoxidation and phenolic radical forms, it affects the quality of food and other natural products; a number of researchers have investigated conditions and possible mechanisms of autoxidation of phenolic compounds.

It is known that one of the most abundant flavonoid in dietary fruits and vegetables, quercetin, has strong antioxidant behavior which is believed to involve initial oxidative steps with subsequent changes in the flavonoid skeleton. Also, many researchers have proved that these changes in structure alter its chemical and biological properties. The group of authors examined how the similarities and differences of quercetin transformation could be affected by the nature of the oxidation systems. In that aspect, they investigated different oxidative processes like autoxidation, enzymatic oxidation with mushroom tyrosinase, electrolysis and chemical oxidation with azodiisobutyronitrile. Later, they analyzed resulting structures by various techniques, such as UV-Vis, LC-MS, GC-MS, and NMR, and final results provided information about products of the transformation of quercetin and their quantities. The comparison of these products in the different systems provided more information about the mechanism involved in the oxidation process, and the results demonstrated that the presence of water, nucleophiles or catalysts, could implicate formation of quinone with subsequent oxidative cleavage or polymerization. The authors indicated that oneelectron oxidation of quercetin anions followed by two fast steps of radical disproportionation and solvent addition on the resulting quinone. ${ }^{8}$

Another type of oxidation of phenols, the catalytic autoxidation by metal ions, has been studied extensively by many authors. In this purpose, different oxidizing agents have been used with different phenols, and the variety of obtained products have been analyzed by several modern techniques.

$\mathrm{Mg}$ (II) ions are ubiquitous in all living cells, so it is of great importance to investigate the influence of the presence of this ion on autoxidation processes of phenols. This was the start point for Nikolic, Veselinovic, and colleagues, who have examined the influence of $\mathrm{Mg}$ (II) ions together with $\mathrm{pH}$ levels, on the formation of gallic acid radicals, using techniques as UV-Vis spectrophotometry and ESR spectroscopy. They observed that lowering the $\mathrm{pH}$ value from 10 to 8.5 changed the mechanism of the autoxidation reaction as evidenced by the different time variations of UV-Vis spectra of solutions. Also, small differences in the UV-Vis spectral changes indicated that the presence of $\mathrm{Mg}$ (II) ions not only affected the electron density of absorbing species but also influenced the overall mechanism of the 
autoxidation reaction. Additionally, the partial characterization was accomplished by computer simulation of ESR spectra of formed free radicals during autoxidation of gallic acid at $\mathrm{pH} 8.5$ in the presence of $\mathrm{Mg}(\mathrm{II})$ ions.9

Some of these authors investigated the same process with a different technique - high-performance liquid chromatography with diode array detection (HPLC-DAD). Data obtained in the study proposed the structure of products gained from autoxidation of gallic acid at $\mathrm{pH} 10$, as some form of gallic acid dimer, while among the minor products, the compound with characteristics similar to ellagic acid had been detectable. Chromatographic results indicated that reaction rate decreased when $\mathrm{pH}$ level was decreased to 8.5 in the presence of $\mathrm{Mg}$ (II) ion and that different autoxidation products was formed, which further indicated that mechanism of the reaction(s) was altered. ${ }^{10}$

In another paper, some of the above-mentioned authors published results on the autoxidation of pyrogallol in weakly alkaline solutions in a $\mathrm{pH}$ range similar to the usual $\mathrm{pH}$ values in the physiological system. With the tools of MCR-ALS, the authors succeeded to explain the autoxidation kinetics and to estimate the pure spectra of species present in the autoxidation processes at the different experimental conditions. Autoxidation of pyrogallol at two $\mathrm{pH}$ levels was examined 7.4 and 8.0. The autoxidation process at $\mathrm{pH} 7.4$ resulted in the formation of purpurogallin, and the same

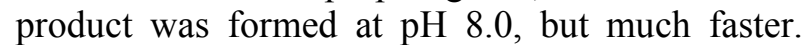
Also, prolonging reaction at $\mathrm{pH} 8.0$ resulted in the formation of a yellow-colored substance, which was, the most probably, purpurogallin polymer, as the authors concluded. ${ }^{11}$

Nikolic and co-workers studied aerial oxidation of catechol (1,2-benzenediol) in an alkaline aqueous solution containing an excess of $\mathrm{Mg}(\mathrm{II})$ ions by electronic absorption spectroscopy. Based on the derived spectra and literature data, the authors concluded that there were two main absorbing species in this system: $\mathrm{Mg}(\mathrm{II})$-spin stabilized o-benzosemiquinone anion radical and C-C dimer formed by the nucleophilic attack of catecholate anion on o-benzoquinone. ${ }^{12}$

Other authors studied the kinetics of the oxidation of catechol by aqueous $\mathrm{Cu}$ (II) as a function of reactant concentrations at $\mathrm{pH}$ range from 6.4 to 7.2. Since oxidation products of o-quinone are able to participate, a spectrophotometric method had been developed to follow the reaction. It was found that monocatecholate complex of $\mathrm{Cu}$ (II) undergoes intramolecular electron transfer, and the rate of the transfer had been investigated. The results had allowed a comparison of the mechanism of autoxidation by aqueous $\mathrm{Cu}$ (II) to the mechanism of enzymatic oxidation with $\mathrm{Cu}$ (II) oxidases. ${ }^{13}$

Influence of another metallic ion, $\mathrm{Ca}(\mathrm{II})$, as well as few more earth elements, on autoxidation of phenol (pyrocatechol), neurotransmitters (dopamine, norepinephrine) and a medication (isoproterenol) were investigated by the group of authors. The effects of $\mathrm{Ca}(\mathrm{II})$ on the free-radical chain reactions were studied using oxygen consumption measurements, EPR-spectroscopy, UV/VIS spectrophotometry, and by potentiometric titration. It was found that formation of $\mathrm{Ca}$ (II)catecholate complexes was accompanied by an increase in the dissociation constants $(\mathrm{Ka})$ of their phenolic hydroxyls. The authors concluded that the presence of alkaline-earth metal cations at $\mathrm{pH}$ level greater than the level of $\mathrm{pKa}$ increased the rate of catecholate oxidation $(\mathrm{Ca}(\mathrm{II}), \quad \mathrm{Mg}(\mathrm{II})>\mathrm{Sr}(\mathrm{II})$, $\mathrm{Ba}(\mathrm{II})$ ), while the presence of the $\mathrm{Zn}$ ions decreased the rate of oxidation. In the latest conclusion, the authors defined the effects of $\mathrm{Ca}(\mathrm{II})$ and other alkaline-earth metal cations on catecholate autoxidation, and pointed that the most important effect was the process of the additional deprotonation of catechol $\mathrm{OH}$-groups that involves in the formation of $\mathrm{Mg}(\mathrm{II})$-catecholate complexes, as later it was exceeded to catechols by dioxygeninduced oxidation. Also, the authors claimed that for chain propagation was responsible the relatively stable free-radical intermediates. ${ }^{14}$

As the prevention of autoxidation of polyphenol and related components is very important for quality control of food and beverages, the group of authors performed the study with the aim to define autoxidation path and steps. In the study they performed the kinetic analysis of the autoxidation of catechins found in green tea, using peroxidasebased bioelectrochemical sensor of hydrogen peroxide $\left(\mathrm{H}_{2} \mathrm{O}_{2}\right)$ and a Clark-type oxygen electrode. The kinetic analysis allowed defining the steps of the mechanism of autoxidation. The first step, as the authors defined, was the oneelectron oxidation of catechins which generated a superoxide anion $\left(\mathrm{O}_{2-}^{-}\right)$and a semiquinone radical, both of which work as catalysts of autoxidation, but which could be suppressed by superoxide dismutase and $\mathrm{H}^{+}$. In the second step, as the authors proposed, $\left(\mathrm{O}_{2}{ }^{{ }^{-}}\right)$was reduced to $\mathrm{H}_{2} \mathrm{O}_{2}$, while the semiquinone radical was then oxidized with $\mathrm{O}_{2}$, and the new amount of $\left(\mathrm{O}_{2}{ }^{-}\right)$ was provided. In the aspect of $\mathrm{pH}$ dependency of autoxidation, the authors concluded that the rate of 
autoxidation could be increased when $\mathrm{pH}$ level is increasing, as the stability of $\mathrm{O}_{2}{ }^{--}$and the semiquinone radical was increased with increasing of $\mathrm{pH}$. The authors also investigated the enhancement of autoxidation by cupric ion. It was found that $\mathrm{Cu}^{2+}$ acted also as a catalyst of the initial oxidation step of catechins and that the product cuprous ion could trigger a Fenton reaction to generate harmful hydroxyl radical. Contrarily, it has been found that borate ion suppressed autoxidation drastically, due to forming of the complex with catechins. ${ }^{15}$

Musie and coworkers were the first to examine the activity of the cobalt Schiff complex as a catalyst in the oxidation of substituted phenol in supercritical $\mathrm{CO}_{2}$. Cobalt(II) Schiff base $\left[\left\{\mathrm{N}, \mathrm{N}^{6}-\right.\right.$ bis(3,5-di-tert-butylsalicylidene)-1,2-cyclohexanediaminato(2-)\} cobalt(II)], $\mathrm{Co}($ salen), acted as a catalyst for autoxidation of 2,6-di-tert-butylphenol (DTBP) and 3,5-di-tert-butylphenol (3,5-DTBP) under the similar experimental conditions: presence of a large excess of $\mathrm{O}_{2}$, total pressure at 207 bar at $70{ }^{\circ} \mathrm{C}$ reaction temperature, and with a reaction time of $21 \mathrm{~h}$. After an eclipsed time, the authors noted that the oxidation of 35-DTBP yielded only trace amounts of products, while on the other hand, DTBP was totally converted to a mixture of DTBQ and the related product of radical coupling $3,5,3^{\prime}, 5^{\prime}$-tetra-tert-butyl-4,4'-diphenoquinone (TTDBQ). They reported the effects on conversion of DTBP to products and on selectivity between the two products in variations of catalyst concentration, oxygen/substrate ratio, temperature, and methylimidazole concentration. The authors concluded that an increase in oxygen concentration increased the selectivity of DTBQ, and that the temperature and the concentration of catalyst didn't affect the selectivity; and finally, that the dioxygen complex was the effective oxidant in both the initial radical formation step and the oxygenation of that radical. The results of this study have shown that supercritical $\mathrm{CO}_{2}$ was a suitable solvent for the cobalt Schiff base catalyzed the oxidation of DTBP, and that with control of the system conditions, some specific products of oxidation could be favored. ${ }^{16}$

\section{Enzyme-catalyzed oxidation of phenols}

Different enzymes have the ability to catalyze the oxidation of phenols by molecular oxygen. Three main classes of the enzymes stand out: the oxidoreductases, the peroxidases, and monophenol monooxygenase. Enzymes from the group of oxidoreductases use diphenols or related compounds as electron donors, and oxygen as the acceptor (catechol oxidase), while the group of peroxidases uses hydrogen peroxide as an electron acceptor to oxidize the donor (horseradish peroxidase), and both groups have the same type of end products - the oxidized donor and water. The group of monooxygenases contains enzymes acting on paired donors, with the incorporation or reduction of molecular oxygen. Example for this group is monophenol monooxygenase, which catalyzes the same reactions as catechol oxidase but using another substrate. ${ }^{6}$

Due to these catalytic properties, many authors had been investigating the application of different oxidative enzymes from bacteria, fungi and plants in numerous waste treatment applications as well in soil remediation.

Duran and Eposito reviewed the papers with this matter, making useful information about the correlation between specific enzymes and specific processes. Some of their points were that peroxidases and/or phenoloxidases act on recalcitrant pollutants by precipitation or transforming to other products, tyrosinase catalyzes the hydroxylation of phenols and dehydrogenation of o-diphenols, while horseradish peroxidase, lignin peroxidase and manganese peroxidase could mineralize a variety recalcitrant aromatic compounds. The authors highlighted that all these processes were improved if the enzymes were immobilized. The good example of immobilization in this review was immobilized enzymes on porous ceramic supports or resins. ${ }^{17}$

Characterization of lignified Zinnia elegans hypocotyls by both alkaline nitrobenzene oxidation and thioacidolysis reveals that coniferyl alcohol units are mainly found as part of 4-O-linked end groups and aryl-glycerol- $\beta$-aryl ether ( $\beta$-O-4) structures. Z. elegans hypocotyls also contain a basic peroxidase (EC 1.11.1.7) capable of oxidizing coniferyl alcohol in the absence of $\mathrm{H}_{2} \mathrm{O}_{2}$. This was the purpose of study led by the group of authors, who showed that the oxidase activity of the $Z$. elegans basic peroxidase was stimulated by superoxide dismutase, and inhibited by catalase and anaerobic conditions. Results also showed that the oxidase activity of this peroxidase was a consequence of an evolutionarily gained optimal adaptation of the enzyme to the $\mu \mathrm{M} \mathrm{H}_{2} \mathrm{O}_{2}$ concentrations generated during the auto-oxidation of coniferyl alcohol, and the stoichiometry of the chemical reaction (mol coniferyl alcohol autooxidized $/ \mathrm{mol} \mathrm{H}_{2} \mathrm{O}_{2}$ formed) was calculated to be 
exactly 0.496 . These results therefore suggested that the $\mathrm{H}_{2} \mathrm{O}_{2}$ generated during the auto-oxidation of coniferyl alcohol was the main factor that drove the unusual oxidase activity of this highly conserved lignin-synthesizing class III peroxidase. ${ }^{18}$

\section{Photo-oxidation}

Heterogeneous photocatalysis is the most commonly applied type of AOP for the degradation of toxic organic compounds. Many organics can be mineralized to water, carbon dioxide and mineral acids by successive hydroxyl radical attack and fragmentation. These radicals can be generated in the system with a heterogeneous photocatalyst, when UV light is applied to the aqueous environment. This makes the process easy to apply to wastewater effluents containing phenols and related compounds. Since biological treatment processes of degradation of phenols have shown to be inefficient, the systems with UV-enhanced photo-degradation using ozone and/or hydrogen peroxide as oxidant have been developed. In this section, we reviewed the literature and focused on the effects of operating parameters such as the initial phenol concentration and $\mathrm{H}_{2} \mathrm{O}_{2}$ addition on the activity of photocatalyst applied, and the results, which determined the kinetics of phenol degradation, were pointed out. All data are additionally summarized in Table 1, presented at the end of the section.

To elucidate kinetics of the oxidative degradation, the group of authors has investigated the effects of $\mathrm{UV} / \mathrm{H}_{2} \mathrm{O}_{2}$ photo-oxidation of phenol and 2- and 4-chlorophenols in dilute aqueous solutions. They determined the kinetics of degradation of the phenolic substrates, and developed mechanistic model for $\mathrm{UV} / \mathrm{H}_{2} \mathrm{O}_{2}$ photo-oxidation. The results showed that degradation rates of phenol were insignificantly small when only UV radiation was applied, as well, when only $\mathrm{H}_{2} \mathrm{O}_{2}$ was added. On the other hand, when synergic effect of $\mathrm{UV} / \mathrm{H}_{2} \mathrm{O}_{2}$ was applied, degradation rates were significantly enhanced. ${ }^{19}$

In addition to kinetics of photolytic degradation of phenols and its dependence of different parameters such as $\mathrm{pH}$, reaction time and initial phenol concentration, the group of authors examined toxicity of products formed during degradation processes to one freshwater planktonic species, Daphnia magna. They concluded that lower $\mathrm{pH}$ and lower concentration of phenol enchased the phenol degradation, while the results of bioassay tests showed that toxicity of effluent from photo-reactor was 2.18 times lower than that obtained with phenol contaminated water before photolysis. ${ }^{20}$

To evaluate rates of consumption of electric power to a mass of phenols photo-degradation, the group of authors used an open up flow slurry reactor and $\mathrm{TiO}_{2}$ loaded with $\mathrm{Ag}$ as a photocatalyst. They determined the optimal conditions in the aspect of the required concentration of photocatalyst, $\mathrm{H}_{2} \mathrm{O}_{2}$ and supply of air, and concluded that each gram of phenol consumed the power of $1,70 \mathrm{~kW}$ for its photodestruction. ${ }^{21}$

Another type of heterogeneous AOP system has been evaluated by the Chen and coworkers. They used $\mathrm{TiO}_{2}$ as photocatalyst supported on the natural inorganic adsorbent, ZSM-5 zeolite, to investigate the ways that $\mathrm{TiO}_{2}$ loaded on an adsorbent high silica zeolite modified the reactions pathways. Depending on the $\mathrm{pH}$ level applied, they confirmed different degradation by-products, and determined that a maximum efficiency of the zeolite supported with photocatalyst was at $\mathrm{pH}=3,4$, while pointed that at higher $\mathrm{pH}$ levels, reactivity was lost. The authors also observed that there was evidence of some polymerization with $\mathrm{TiO}_{2}$ on the adsorbent zeolite support in base that could interfere with mineralization. ${ }^{22}$

The group of authors used experimental data obtained from the open literature of an actual $\mathrm{UV} / \mathrm{H}_{2} \mathrm{O}_{2}$ process to validate a dynamic kinetic model for the oxidation of phenols in water by a $\mathrm{UV} / \mathrm{H}_{2} \mathrm{O}_{2}$ process. Using those data and the developed kinetic model, the authors estimated kinetic rate constants for phenol intermediates, catechol, and hydroquinone, and reported an optimal initial hydrogen peroxide concentration. ${ }^{23}$

Improvement of oxidative decomposition of aqueous phenol in a $\mathrm{UV} / \mathrm{H}_{2} \mathrm{O}_{2}$ system by microwave irradiation was examined by the group of authors. Based on the experimental results, the authors drew the conclusion that microwave irradiation could raise phenol conversion efficiency up to or above $50 \%$, regardless suppression of thermal effect, and it could accelerate the degradation rate of intermediates, like hydroquinone and catechol. They also showed that the addition of hydrogen peroxide by more than a stoichiometric amount could mineralize aqueous phenol to create a short reaction time. Results from the kinetic analysis allowed the conclusion that in the absence of microwave irradiation, dominant was an indirect reaction of phenol with $\mathrm{OH}$ radical, while in the presence of microwave irradiation dominant was a direct reaction of phenol with hydrogen peroxide. ${ }^{24}$ 
Table 1

Photocatalytic degradation of different organic compounds by heterogeneous photocatalysts

\begin{tabular}{|c|c|c|c|}
\hline Compound & Type of system & $\begin{array}{c}\text { Results and observation } \\
\end{array}$ & Ref. \\
\hline $\begin{array}{l}\text { Phenol, } \\
\text { 2- and 4- } \\
\text { chlorophenol }\end{array}$ & Photo-reactor & $\begin{array}{l}\mathrm{UV} / \mathrm{H}_{2} \mathrm{O}_{2} \text { addition have increased degradation rates of } \\
\text { compounds. }\end{array}$ & [19] \\
\hline Phenols & Photo-reactor & $\begin{array}{l}\text { Bioassay tests showed that toxicity of effluent from photo-reactor } \\
\text { was } 2.18 \text { times lower than that obtained before photolysis. }\end{array}$ & [20] \\
\hline Phenols & $\mathrm{TiO}_{2}$ loaded with $\mathrm{Ag}$ & $\begin{array}{l}\text { Established optimal conditions in the aspects of the required } \\
\text { concentration of photocatalyst, } \mathrm{H}_{2} \mathrm{O}_{2} \text { and supply of air, and } \\
\text { electricity consumption rates. }\end{array}$ & [21] \\
\hline $\begin{array}{l}\text { Phenols, } \\
\text { Benzen }\end{array}$ & $\begin{array}{l}\mathrm{TiO}_{2} \text { as photocatalyst } \\
\text { supported on } 2 \mathrm{SM}-5 \\
\text { zeolit }\end{array}$ & $\begin{array}{l}\text { The polymerisation of } \mathrm{TiO}_{2} \text { and sorbent could interfere with } \\
\text { mineralisation. Maximum efficiency was estimated at } \mathrm{pH}=3,4 \text {. }\end{array}$ & [22] \\
\hline Phenols & Addition of $\mathrm{H}_{2} \mathrm{O}_{2}$ & $\begin{array}{l}\text { Kinetic rate constants for phenol intermediates, catechol and } \\
\text { hidroquinone, and reported one optimal initial } \mathrm{H}_{2} \mathrm{O}_{2} \text { concentration. }\end{array}$ & [23] \\
\hline Phenols & $\begin{array}{l}\text { Microwave-assisted } \\
\text { photo-reactor }\end{array}$ & $\begin{array}{l}\text { Microwave irradiation raise phenol conversion up to or above } \\
50 \% \text {, and accelerate the degradation rate of intermediates, like } \\
\text { hydroquinone and catechol. In the absence of microwave } \\
\text { irradiation, dominants were one indirect reaction of phenol and } \\
\mathrm{OH} \text { radical; while in the presence microwave irradiation dominant } \\
\text { is a direct reaction of phenol with } \mathrm{H}_{2} \mathrm{O}_{2} \text {. }\end{array}$ & [24] \\
\hline Tyrosole & $\begin{array}{l}\text { Catalyst system based } \\
\text { on Al-Fe pillared clay }\end{array}$ & $\begin{array}{l}\text { The catalyst was efficient for total removal of tyrosol, without } \\
\text { significant leaching of iron ions; and pseudo-first order kinetic } \\
\text { model corresponded with experimental results. }\end{array}$ & [25] \\
\hline Humic acids & $\begin{array}{l}\text { UV source-low- } \\
\text { pressure mercury } \\
\text { vapor lamps }\end{array}$ & $\begin{array}{l}\text { The addition of } \mathrm{H}_{2} \mathrm{O}_{2} \text { improved significantly the efficiency of the } \\
\text { humic acid degradation by UV light with the optimal } \mathrm{H}_{2} \mathrm{O}_{2} \\
\text { concentration of } 0.01 \mathrm{~mol} \cdot \mathrm{dm}^{-3} \text {. UV light intensity had a positive } \\
\text { correlation with the process efficiency, while pH levels correlated } \\
\text { with a negative effect. Carbonate and bicarbonate ions inhibited } \\
\text { degradation of humic acid, but nitrate ions did not have impact up } \\
\text { to the concentration of } 5 \mathrm{mmol} \cdot \mathrm{dm}^{-3} \text {. }\end{array}$ & [26] \\
\hline Humic acids & $\begin{array}{l}\text { Batch reactor aligned } \\
\text { with ten of low- } \\
\text { pressure UV pressure } \\
\text { mercury vapor lamps }\end{array}$ & $\begin{array}{l}\text { Increasing of humic acid concentration have the negative effect on } \\
\mathrm{UV} / \mathrm{H}_{2} \mathrm{O}_{2} \text { oxidation, } 80-90 \% \text { of the humic acids was removed } \\
\text { within } 30 \mathrm{~min} \text { of photolysis with an addition of } \mathrm{H}_{2} \mathrm{O}_{2} \text { at the } \\
\text { optimal level of } 0.01 \mathrm{~mol} \cdot \mathrm{dm}^{-3} \text {, while its increased levels did not } \\
\text { improve degradation. }\end{array}$ & [27] \\
\hline Humic acids & $\begin{array}{l}\text { Batch reactor aligned } \\
\text { with ten of low- } \\
\text { pressure UV pressure } \\
\text { mercury vapor lamp of } \\
450 \mathrm{~W}\end{array}$ & $\begin{array}{l}\text { Lower dosage of the } \mathrm{H}_{2} \mathrm{O}_{2} \text { had the greater impact to the amount of } \\
\text { humic acids photolyzed, while aeration did not. Carbonate species } \\
\text { suppressed the humic acids removal. }\end{array}$ & [28] \\
\hline
\end{tabular}

To optimize the process for catalytic photooxidation of tyrosol, with the specially created type of catalyst system based on $\mathrm{Al}-\mathrm{Fe}$ pillared clay, the group of authors performed the tests on a laboratory scale set-up. They investigated the influence of the concentrations of the catalyst, tyrosol pollutant and $\mathrm{H}_{2} \mathrm{O}_{2}$, and the levels of $\mathrm{pH}$ and temperature, and found that a pseudo-first-order kinetics model corresponded with experimental results, and that conditions with oxidant content lower than stoichiometric (28\%), with the catalyst based on (Al-Fe) pillared montmorillonite, was efficient for total removal of tyrosol, without significant leaching of $\mathrm{Fe}$ ions. ${ }^{25}$

Based on reviewed studies, it can be concluded that degradation of phenols and their by-products can be sufficiently efficient in heterogeneous AOP systems, with both UV stimulation, oxidant addition at optimal concentration and photocatalyst based both on semiconductor properties as in the case of $\mathrm{TiO}_{2}$, or metal doped inorganic silicates.

While phenols have origin from industrial effluents, in natural waters other class of organic compound can be found, and many of them are byproducts of decompositions of plant material, so besides phenols, the content of humic acids(HA), in fresh waters must be monitored regularly. Humic acids are actually a group of highmolecular-weight organic compounds, which have originated from soil, peat, and coal. HA is characterized by an ability to bind heavy metals. Long-term human consumption of HA-rich water 
may cause damage to endothelial cells and subsequent chronic health problem, so it is crucial to remove this compounds from effluents, so balance in natural waters wouldn't be disrupted.

Another $\mathrm{UV} / \mathrm{H}_{2} \mathrm{O}_{2}$ process in aqueous solution was investigated by Veselinovic and the group of authors to determine process efficiency of degradation of the humic acids (HA), which was monitored by the UV/VIS spectrophotometric analysis of the HA residual concentration. As the UV source, low-pressure mercury vapor lamps with the emission maximum at $253,7 \mathrm{~nm}$ was applied. They observed that without $\mathrm{H}_{2} \mathrm{O}_{2}$ presence, UV radiation had a negligible effect on the residual content of $\mathrm{HA}$ in aqueous solutions, and that, on the other hand, the addition of $\mathrm{H}_{2} \mathrm{O}_{2}$ improved significantly the efficiency of the $\mathrm{HA}$ degradation by UV light and the optimum $\mathrm{H}_{2} \mathrm{O}_{2}$ concentration of $0,01 \mathrm{~mol} \mathrm{dm}^{-3}$ was established. They had investigated the effect of increasing certain parameters on the process efficiency, so they concluded that UV light intensity had positive correlation with the process efficiency, while the increase of $\mathrm{pH}$ had the negative effect. Presence of certain ions showed that the degradation of HA could be totally inhibited when the carbonate and bicarbonate ions were present and that nitrate ions had no effect when present up to the concentration of $5 \mathrm{mmol} \mathrm{dm}^{-3}$. ${ }^{26}$

A similar experiment was conducted by Veselinovic and the other group of authors, with the difference of design of the photoreactor, which in this case had, although the same type of UV source, the ten of low-pressure UV pressure mercury vapor lamps aligned in a batch reactor. The results from monitoring the residual concentration of HA, confirmed the conclusions of the authors from previous experiment mentioned above, but also contributed with the conclusion that the increasing of HA concentration had a negative effect on $\mathrm{UV} / \mathrm{H}_{2} \mathrm{O}_{2}$ oxidation due to the absorption of UV radiation and scavenging of hydroxyl radicals, while the addition of $\mathrm{H}_{2} \mathrm{O}_{2}$ significantly improved efficiency of HA degradation by UV light, and they pointed that $80-90 \%$ of the HA was removed within 30 min of photolysis. Also, they showed that excessive dosage of $\mathrm{H}_{2} \mathrm{O}_{2}$ didn't improve the degradation of $\mathrm{HA}$ and established the optimum $\mathrm{H}_{2} \mathrm{O}_{2}$ dose of 0,01 moldm $^{-3}$ for HA oxidation. ${ }^{27}$

Another experiment was conducted to evaluate the $\mathrm{UV} / \mathrm{H}_{2} \mathrm{O}_{2}$ oxidation process for the removal of humic acids in water, by the groups of authors. In this experiment, in the batch photoreactor as a light source, the 450-W UV lamp with high-pressure mercury vapor was employed. The results after analyzing the residuals of humic acids showed that the presence of $\mathrm{H}_{2} \mathrm{O}_{2}$ promoted the degradation efficiency, in the aspect that lower dosage of the $\mathrm{H}_{2} \mathrm{O}_{2}$ had the greater impact to the amount of humic acids photolyzed, but that the excessive dosage of $\mathrm{H}_{2} \mathrm{O}_{2}$ had no impact to the degradation rate. The authors also investigated the influence of aeration with air, and concluded that it didn't promote the removal efficiency of humic acids, while the presence of carbonate species suppressed the HAs' removal, a resulted with a larger amount of $\mathrm{H}_{2} \mathrm{O}_{2}$ decomposition. ${ }^{28}$

Since humic acids are ubiquitous in aquatic and soil environments, it is of a great concern to define the degradation characteristics of HA. It is known that the photosensitization of humic acids yields active oxygen species, such as singlet oxygen, ${ }^{1} \mathrm{O}_{2}$, hydroxyl radicals, $\mathrm{HO} \cdot$, hydroperoxyl radicals, $\mathrm{HO}_{2} \bullet$, and superoxide $\mathrm{O}^{2-} \cdot{ }^{29}$ Such species give rise to the generation of $\mathrm{H}_{2} \mathrm{O}_{2}$ in the environment, which also contaminates ground waters, and affects the living world. The experiments with batch reactors an UV lights showed significant efficiency in degradation of humic acids and thus preventing additional pollution of the aqueous environment.

\section{Electrochemical oxidation}

For the degradation of phenolic compounds from the wastewater effluents, electrochemical oxidation is one of the most attractive technique, as it is known as a clean, versatile and powerful method. When in the focus of wastewater treatment are organic compounds, electrochemical oxidation is, in fact, an anodic process in aqueous solution. Electrode material should have the high electrochemical activity for aromatic ring opening and low electrochemical activity for further oxidation of the aliphatic carboxylic acids which are mostly biocompatible. ${ }^{30}$

Systems for wastewater treatment which use electrochemical oxidation as a major method should have a great efficiency of pollutant reduction and the process should be economically payable. These systems can operate in either batch or continuous conditions, but favorable are systems that could completely oxidize the organic pollutants to $\mathrm{CO}_{2}$ by hydroxyl radicals, as it is shown in Figure 3. 


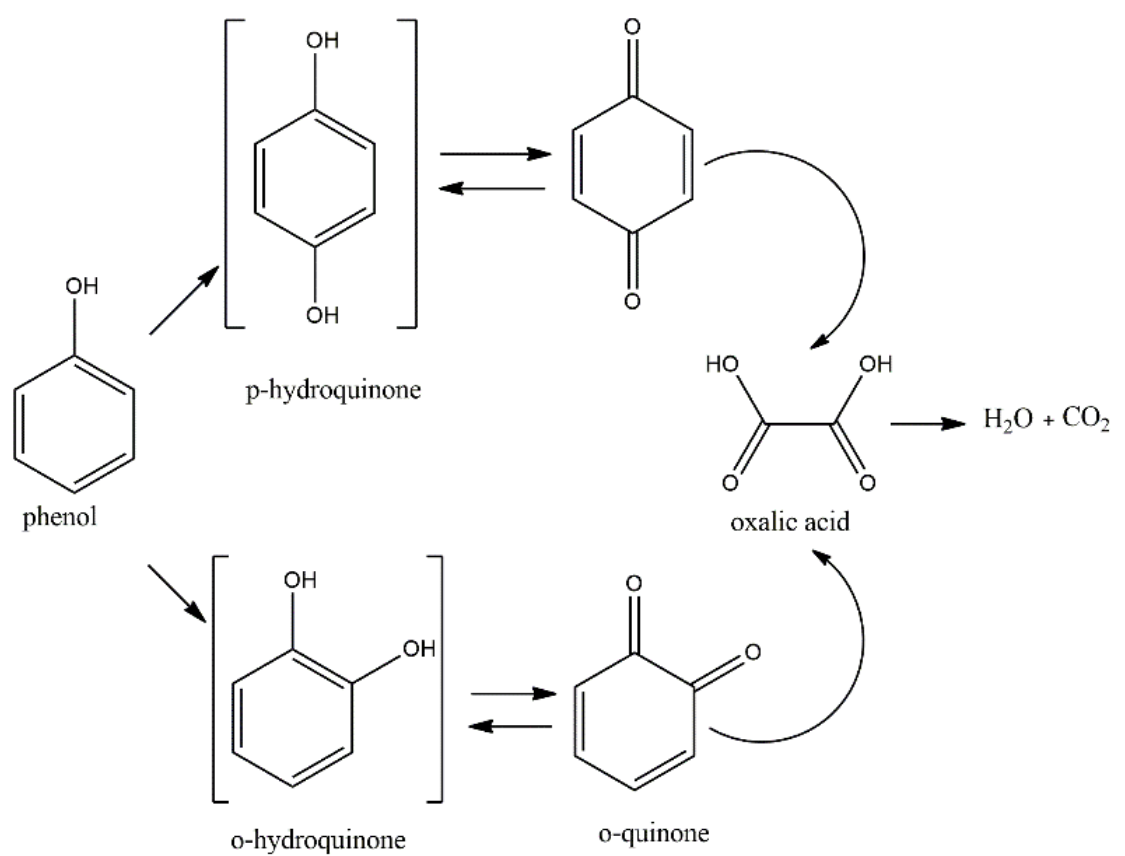

Fig. 3 - Schematic representation of electrochemical phenol degradation processes .

Many studies of electro-oxidation of numerous phenolic compounds, employed a number of anode materials, including: C, B, Mn, Co, noble/seminoble (Pt, Ir, $\mathrm{Ru})$, transitional metals ( $\mathrm{Ti}, \mathrm{Sb}, \mathrm{Sn}$, $\mathrm{Pb})$, their oxides and mutual composition, like boron-doped diamond, BDD. In the focus of studies, we reviewed was mostly the impact of current density and phenol concentration in the solution, on the decomposition rates, which a number of authors investigated by analyzing byproducts, and energy costs of the processes when different electrochemical methods were applied. ${ }^{31}$

The common techniques for examination of the electrochemical oxidation of phenol in aqueous solution are cyclic voltammetry and chronoamperometry. Comninellis and colleagues used a vitreous carbon electrode to examine the kinetic aspect of the phenol oxidation as a function of its concentration and temperature, in the range of 25$85^{\circ} \mathrm{C}$. By monitoring the decrease in the peak current of phenol oxidation during the course of successive potential scans, they found that formation of a polymeric film on the electrode surface, led to its deactivation and that it couldn't be activated again, neither with repeating the scans nor by temperature change. The electrochemical activity of the electrode was partially restored, solely with different potentials of chronoamperometry, in the region of water decomposition, even when performed at low temperature $\left(25^{\circ} \mathrm{C}\right) .{ }^{32}$

Different electrodes, but the same technique was employed by the Panizza and coworkers, for the oxidation of 2-naphthol. The authors used a range of electrode materials such as $\mathrm{Ti} / \mathrm{Ru} / \mathrm{Sn}$ ternary oxide, $\mathrm{PbO}_{2}$, and $\mathrm{BDD}$ anodes. They confirmed the presence of the polymeric films by IR spectroscopy and examined the possibilities of reactivation of the electrodes. They found that $\mathrm{PbO}_{2}$ and BDD could be restored to their activity from the beginning of electro-oxidation, by simple anodic treatment in the potential region of electrolyte decomposition, and that BDD deactivation was less intensive thus its reactivation was easier and faster. They also found that the $\mathrm{Ti} / \mathrm{Ru} / \mathrm{Sn}$ ternary oxide surface couldn't be reactivated, under any circumstances. ${ }^{33}$

In a similar experiment, the same group of authors examined electro-oxidation of 2-naphthol mediated by active chlorine, which was electrogenerated in situ on a Ti/Ru/Sn ternary oxide. This time, they used galvanostatic electrolysis under different experimental conditions. To examine products of oxidation they measured chemical oxygen demand (COD), and for analyzing byproducts, the authors employed techniques as HPLC and GC. The authors found that in absence of $\mathrm{NaCl}$, it was possible to oxidize only a small fraction of 2-naphthol by direct electrolysis, but with the generation of chloride, the rate of naphthol oxidation significantly increased, both with chloride concentration and $\mathrm{pH}$, which could lead to complete oxidation. On the other hand, it was confirmed that the rate of naphthol oxidation was independent of current density. HPLC and GC 
data showed that organochlorinated compounds had been formed, but also that were further completely oxidized. ${ }^{34}$

Comninellis and Pulgarin showed by analysis of reaction intermediates and a carbon balance of the electrochemical oxidation of phenol at a platinum anode, that there were two parallel pathways for the reaction; chemical oxidation with electro-generated hydroxyl radicals and direct combustion of adsorbed phenol or/and its aromatic intermediates to $\mathrm{CO}_{2} \cdot{ }^{35} \mathrm{In}$ another study, the same authors with the same parameters of examination, only with the difference they used doped $\mathrm{SnO}_{2}$ anodes this time, showed that the main reaction was oxidation of phenol to $\mathrm{CO}_{2}$. They explained that during anodic polarization, the change of the chemical structure of the electrode surface occurred, which was the reason for such characteristic of the $\mathrm{SnO}_{2}$ anode. ${ }^{36}$ Panizza and coworkers employed both bulk electrolysis and cyclic voltammetry for examination of electrochemical characteristics of a synthetic boron-doped diamond thin film electrode (BDD) in acid media containing phenol. The results showed that in the potential region of water stability on BDD surface resulting in electrode a polymeric film was formed and that this could be inhibited by the generation of hydroxyl radicals. The authors concluded that these hydroxyl radicals could lead either to the combustion of phenol or to the selective oxidation of phenol to benzoquinone, depending on the experimental conditions, which was in correspondence with the known theoretical model. $^{37}$

To simulate the electrolytic degradation process of phenol in aqueous solution, Wang and colleagues used three kinds of Ti-based $\mathrm{PbO}_{2}$ electrodes with or without $\mathrm{SnO}_{2}+\mathrm{Sb}_{2} \mathrm{O}_{3}$ interlayers, which were prepared by the thermal decomposition of $\mathrm{Pb}\left(\mathrm{NO}_{3}\right)_{2}$ solution. The experimental results showed that removal rate of phenol, the COD values, and the instantaneous current efficiency were not significantly different between types of electrodes and that the cell voltages for the anodes with the interlayers were lower than that without the interlayers. The authors showed also that prolongation of the electrolysis time decreased the current efficiencies of electrolysis process for the three kinds of electrodes, while the results obtained by cyclic voltammetry showed that interlayers of the $\mathrm{SnO}_{2}+\mathrm{Sb}_{2} \mathrm{O}_{3}$ on each electrode improved its electrocatalytic activity and the accelerated lifetime. ${ }^{38}$

The Lin and coworkers examined the effects of $\mathrm{Ti} / \mathrm{PbO}_{2}$ and $\mathrm{Ti} / \mathrm{Ru}-\mathrm{Ti}-\mathrm{Sn}$ oxide electrodes, on the electrochemical oxidation reactions and reaction intermediates of phenol, in aqueous solution, by using UV-Vis spectroscopy. They used HPLC technique for the determination of by-products, and confirmed the generation of hydroquinone and pyrocatechol, which were oxidized further. ${ }^{39}$

Cestarolliand colleagues investigated the electrochemical oxidation of phenolate $\mathrm{Ti} / \mathrm{Ru}(0,3) \mathrm{Pb}((0,7-\mathrm{x})) \mathrm{Ti}(\mathrm{x}) \mathrm{O}(\mathrm{y})$ oxide electrodes. They also employed cyclic voltammetry and electrolysis in acidic media as a function of the electrode composition. The results obtained from the cyclic voltammetry showed that increased content of $\mathrm{Pb}$ led to the increased electrocatalytic response of the electrode and that the lowest rate of phenol degradation was in the complete absence of $\mathrm{Pb}$ in the composition of the electrode. On the other hand, the authors confirmed that presence of $\mathrm{PbO}(\mathrm{x})$ led to large phenol degradation, and established that optimum compositions for electrodes in the aspect of $\mathrm{Pb}$ and $\mathrm{Ti}$ content was $\mathrm{Ti} / \mathrm{Ru}(0,3) \mathrm{Pb}(0,5) \mathrm{Ti}(0,2) \mathrm{O}(2)$ and $\mathrm{Ti} / \mathrm{Ru}(0,3) \mathrm{Pb}(0,7) \mathrm{O}(2)$, for the highest yields of total organic carbon. ${ }^{40}$

When the systems with electrochemical processes are used for removal of phenols and other organic pollutants, it is important to wisely choose the anodic material, having in mind that material is prone to polymeric film formation. The other aspect when it is about of selection of anodic material is to pick one which can be easily restored and reactivated or to find other kinds of approach to inhibit polymerization in the first place, like addition and generation of hydroxyl radicals.

\section{Oxidation by Fenton's reagent}

Fenton's reaction was named by its discoverer, Fenton in XIX century. Fenton then observed oxidation of tartaric acid by $\mathrm{H}_{2} \mathrm{O}_{2}$ in the presence of iron ions, and pointed that with hydrogen peroxide, the iron salt could work as catalyst, for the oxidation of organic molecules. This type of reaction is very common in both chemical and biological systems and in many natural environments. Nevertheless, its application as an oxidizing process for destroying hazardous organics was not applied until the late $1960 \mathrm{~s}^{41}$

Today, it is suggested several reaction mechanisms for different organic molecules. It is known that in Fenton reaction produces hydroxyl radical by the general reaction scheme:

$$
\mathrm{H}_{2} \mathrm{O}_{2}+\mathrm{Fe}^{2+} \rightarrow \mathrm{OH}^{\bullet}+\mathrm{OH}^{-}+\mathrm{Fe}^{3+}
$$

Additionally, when UV irradiation is performed, in the process known as photo Fenton oxidation, 
hydroxyl radical can be a product of direct photolysis of $\mathrm{Fe}(\mathrm{OH})^{2+}$ ion, which can be formed in the previous reaction. ${ }^{29}$

Industrial use of Fenton process as an advanced oxidation method for the treatment of wastewaters was reviewed by the group of authors. They presented that this kind of pollutant removal is adequate for final polishing that allowed further biological treatment. The authors also showed that this technology is suitable for wide diversity of effluents from chemical and other related industries or activities, including pharmaceutical, pulp and paper, textile, food, cork processing, and landfilling among others. ${ }^{42}$

Zazo and colleagues, in the paper based on the phenol oxidation by Fenton's reagent in aqueous solution, under various operating conditions. They assumed that the aromatic ring could be initially hydroxylated which could yield to formation of dihydroxybenzenes, mainly catechol and hydroquinone in redox equilibrium with benzoquinones. Further, opening of catechol rings could make muconic acid, that could oxidize to maleic and fumaric acids. In condition in which $\mathrm{Fe}^{2+}$ and $\mathrm{H}_{2} \mathrm{O}_{2}$ are present in high concentrations, the oxidation of formic acid to $\mathrm{CO}_{2}$ and $\mathrm{H}_{2} \mathrm{O}$ is favored, while oxalic acid would remain in the solution. ${ }^{5}$

Instead of phenols, Fukushima and coworkers studied the impact of photo Fenton processes to pathways degradation and changes in the molecular and structural characteristics of humic acid. They started with previous knowledge that HAs could photochemically reduce naturally occurring $\mathrm{Fe}(\mathrm{III})$ ions to $\mathrm{Fe}(\mathrm{II})$. The authors observed based on FTIR characteristic bends, that iron might bind to humic acid molecule, and that phenolate anions could oxidize further to phenoxy radicals during the photoreduction of $\mathrm{Fe}$ (III) to $\mathrm{Fe}(\mathrm{II})$ and the attack of $\mathrm{HO}^{\circ}$. Then, phenoxy radicals could yield nonradical products, such as coupling compounds. They proposed two mechanisms of $\mathrm{HO}^{\circ}$ reaction with $\mathrm{HA}$, one when the radical was added to aromatic ring, thus yielding to coupling products, or ring-opened product, and another, when hydrogen atom was abstracted from alkyl groups $(\mathrm{RH})$ yielding organic radicals $\left(\mathrm{R}^{\circ}\right)$, which were readily oxidized to peroxy radicals $\left(\mathrm{RO}_{2}{ }^{\circ}\right)$ in the presence of $\mathrm{O}_{2}$. These radical species could be added to unsaturated groups in HA, and the resulting dialkyl peroxide was then auto degraded to $\mathrm{RO} \bullet$ and epoxide. ${ }^{29}$

In Fukushima study, as representative of a phenolic industrial wastewater, initial phenol concentration of $100 \mathrm{mg} / \mathrm{L}$ was used under working conditions of temperature 25 and $50{ }^{\circ} \mathrm{C}$, and $\mathrm{pH}$ value of 3 . While phenol concentration was set, the $\mathrm{H}_{2} \mathrm{O}_{2}$ and the $\mathrm{Fe}^{2+}$ doses varied 1-10 times the stoichiometric ratio. As mentioned above, the authors identified intermediates, and their difference depending on operating $\left(\mathrm{H}_{2} \mathrm{O}_{2}\right.$ and $\mathrm{Fe}^{2+}$ concentrations), together with TOC levels. They observed that the difference decreased as the doses of $\mathrm{H}_{2} \mathrm{O}_{2}$ and $\mathrm{Fe}^{2+}$ increased, which indicated that oxidation intermediates must be forms between phenol and the organic acids. ${ }^{5}$

As Fenton's reagent has confirmed to be a feasible technique for denaturation of phenolic compounds in many food industry wastewaters, Rivas and coworkers used $p$-hydroxybenzoic acid as a model compound to investigate influence of typical operating variables (reagent concentrations and flowrate, temperature and $\mathrm{pH}$ ), the kinetics of the process and intermediates formed during the reaction. Experiments were carried out in the dark, and $p$-hydroxybenzoic acid was oxidized by continuously pumping two solutions of ferrous iron and hydrogen peroxide. Calculated results suggested the presence of parallel routes of substrate elimination and/or initiating rate constant with a higher value, when compared to the classical Fenton's chemistry, like oxidizing species different from the hydroxyl radical. Simultaneous Fenton's or $\mathrm{UV} / \mathrm{H}_{2} \mathrm{O}_{2}$ oxidations of $p$-hydroxybenzoic acid, tyrosol and $p$-coumaric acid confirmed the presence of reactions different from the hydroxyl radical oxidation. ${ }^{43}$

A similar study, in the aspect of parameters that were examined ( $\mathrm{pH}$ and reagent concentration), but in batch conditions, and with phenol as a model compound, was performed by Kavitha and Palanivelu in simulated and industrial wastewater. They compared mineralization efficiency in the Fenton oxidation, solar-Fenton and UV-Fenton, and confirmed the mineralization efficiency was very high in solar and UV Fenton processes. The same intermediates were identified in both solar and UV Fenton oxidation in the early stages (carboxylic acids like acetic acid and oxalic acid), while the same molecules were the end product of Fenton process. Additionally, complete degradation in solar and UV light Fenton was achieved with significantly less concentration of iron ion which was favored in the terms of pollution management. ${ }^{44}$

Photochemically enhanced Fenton process for phenol degradation was investigated by Feng and Lecheng. They compared UV-VIS spectra of phenol degradation and observed the difference between photo-Fenton process and $\mathrm{UV} / \mathrm{H}_{2} \mathrm{O}_{2}$. They proposed a 
possible pathway diagram for phenol degradation in photo-Fenton process and established optimal operating parameters for chemical oxygen demand (COD) removal, such as dosage of $\mathrm{H}_{2} \mathrm{O}_{2}$ and iron ions, $\mathrm{pH}$ and suitable carrier gas. The results regarding kinetic parameters showed that complex degradation of phenol was the main pathway for removal of COD, and that hydroxyl radicals had not had significant impact in the photo-Fenton degradation of phenol. ${ }^{45}$

To investigate parameters of optimization and kinetic modeling, Ayodele and coworkers used had phosphoric acid modified kaolin clay supported ferric-oxalate catalyst (AMKC) for phenol degradation. They used X-ray diffraction, Fourier Transform Infrared Spectroscopy, XRF and EDX results to confirm the presence of $\mathrm{Fe}$, while Scanning Electron Microscopy (SEM) results showed that acid modification led to structural and morphological changes. The authors determined the best optimization result condition to achieve $99,15 \%$ degradation of $100 \mathrm{ppm}$ initial concentration of phenol, at $30^{\circ} \mathrm{C}$ in $5 \mathrm{~min}$ reaction time,as $18,2 \%$ excess $\mathrm{H}_{2} \mathrm{O}_{2}, 2,23 \mathrm{~g}$ of AMKC. Kinetic study revealed that the degradation rate of $50 \mathrm{ppm}$ was 1,38 times faster than $200 \mathrm{ppm}$, and that the selectivity of AMKC was 3,4 times higher than through intermediates. The authors also repeated experiments for reusability studies, and concluded that AMKC was reliable catalyst for phenol degradation, as after 5 experiments, the activity of AMKC decreased by only about $4 \% .{ }^{46}$

Babuponnusami and Muthukumar in the study compared the performance of Fenton, electro-Fenton, sono-electro-Fenton and photo-electro-Fenton processes for the degradation of phenol. They investigated the effect of operating parameters such as hydrogen peroxide concentration, $\mathrm{Fe}^{2+}$ concentration, current density, initial phenol concentration and $\mathrm{pH}$ levels of solution. The highest degradation efficiency was observed in photo-electro-Fenton, significantly higher in sono-electro-Fenton then in electro-Fenton, while solely Fenton showed the lowest efficiency. Additionally, the time eclipse for complete degradation was investigated, and the authors concluded that in the case of photo-electroFenton degradation was the fastest, and the process of sono-electro-Fenton, required insignificantly more time, while Fenton and electro-Fenton processes required noticeable greater amount of time. ${ }^{47}$

Photochemical systems may be used in a homogeneous solution. Nevertheless, all types of Fenton process need addition of iron ions as catalyst, which is undesired in the treated water, and hydrogen peroxide which is consumed being a significant cost in this process. The main problems with Fenton processes are in the aspect of sludge disposal, and requirement of continuous supply of chemicals, and cost of process itself.

\section{Oxidative processes applications in general and for wastewater treatment}

Phenols are considered as priority pollutants since they are harmful to organisms at low concentrations and many of them have been classified as hazardous pollutants because of their potential to harm human health. It should be noted that the contamination of drinking water by phenols, at even a concentration of $0.005 \mathrm{mg} \mathrm{L}^{-1}$ could bring about significant taste and odor problems making it unfit for use. A representative of this class of compounds is phenol. Sources of phenol include the discharges of chemical process industries such as coal gasification, polymeric resin production, oil refining, coking plants, paper mill, herbicides and fungicides production. ${ }^{48}$ Human consumption of phenol-contaminated water can cause severe pains leading to damage of capillaries ultimately causing death. Phenol containing water, when chlorinated during disinfection of water also results in the formation of chlorophenols. Traditional wastewater treatment methods like biological treatment, adsorption and stripping cannot readily mineralize phenols. Advanced oxidation processes (AOPs), being able to solve the problem of phenol destruction in aqueous systems were more and more checked during the last decade. Among AOPs, heterogeneous photocatalysis using $\mathrm{TiO}_{2}$ as photocatalyst appears as the most emerging technology for phenol degradation. ${ }^{49}$

The comparison of techniques of Advanced Oxidation Processes $\left(\mathrm{O}_{3}, \mathrm{O}_{3} / \mathrm{H}_{2} \mathrm{O}_{2}, \mathrm{UV}, \mathrm{UV} / \mathrm{O}_{3}\right.$, $\mathrm{UV} / \mathrm{H}_{2} \mathrm{O}_{2}, \mathrm{O}_{3} / \mathrm{UV} / \mathrm{H}_{2} \mathrm{O}_{2}, \mathrm{Fe}^{2+} / \mathrm{H}_{2} \mathrm{O}_{2}$ and photocatalysis) for degradation of phenol was performed by Esplugas and coworkers. They tested the parameters like $\mathrm{pH}$ influence, kinetic constants, stoichiometric coefficient and optimum oxidant/pollutant ratio, and found that the fastest process for phenol degradation was with Fenton reagent, the lowest costs were obtained with ozonation, while the highest degradation rate were obtained with combination of $\mathrm{UV} / \mathrm{H}_{2} \mathrm{O}_{2}{ }^{50}$

Since a number of studies showed that the effectiveness of the catalytic photooxidation of pollutants was influenced by the addition of metal ions and their complexes. ${ }^{51}$ Sýkora and colleagues 
investigated the role of metal ions and their complexes in the photo-oxidation of phenols in homogeneous solution. The authors reviewed the effects of different ions and complexes $(\mathrm{Cu}$ (II), $\mathrm{Ag}(\mathrm{I}), \mathrm{Fe}(\mathrm{III}), \mathrm{Ru}(\mathrm{bpy}))$, in both homogeneous and heterogeneous - phenol, chlorophenol and nitrophenol systems. They showed that the presence of metal ions significantly influenced the effectiveness of phenol photo-degradation or photomineralization and summarized the role and influence of $\mathrm{M}^{\mathrm{n}+}$ ione in such systems, as positive due to its electron trapping efficiency, and in presence of $\mathrm{O}_{2}$ by ${ }^{\bullet} \mathrm{OH}$ radical formation. Additionally, the enhancement with the metal complexes they explained as result of high chemical reactivity of the ternary complex, and they pointed the $\mathrm{Cu}(11) / \mathrm{Cu}(\mathrm{I})$ redox cyclic processes as of great significance. ${ }^{52}$

Huang and coworkers investigated four AOP systems: $\mathrm{H}_{2} \mathrm{O}_{2} / \mathrm{Fe}^{2+}, \quad \mathrm{TiO}_{2} / \mathrm{UV} / \mathrm{O}_{2}, \mathrm{H}_{2} \mathrm{O}_{2}$, and $\mathrm{TiO}_{2} / \mathrm{UV} / \mathrm{H}_{2} \mathrm{O}_{2}$ and their potential for degradation of chlorophenols from wastewater flow. The authors generalized a reaction scheme, specifically, ones involving hydroxyl radicals. They presented that the free radical, $\operatorname{Ar}(\mathrm{OH})_{2} \mathrm{Xn}$, which was formed after the attack of a halogenated phenol by a hydroxyl radical, $\mathrm{OH} \cdot$, could later undergo two reaction paths: one path was hydroxylation without dechlorination, which they called Type A reaction and the other reaction of hydroxylation with dechlorination, which was called Type B. The authors pointed that that mono-halogenated phenols would only follow Type A path, and that dichlorophenols and trichlorophenols could have both Type A and Type B reaction pathways; while tetrahalogenated and pentahalogenated phenols would only follow Type B reaction pathway. ${ }^{4}$

To discover effectiveness of the degradation of humic acid (HA) in aqueous solution, by electrochemical and photoelectrochemical oxidation, Pinhedo and colleagues carried out experiments using electrolysis and photo-assisted electrolysis on a thermally prepared oxide electrode mounted in a flow cell reactor. Results showed similar effectiveness, but the total organic carbon (TOC) reduction rate was significantly better by assisting electrolysis with UV radiation, and the decrease during the photo-electrolysis reached $65 \%$ at the same current density and processing time. ${ }^{53}$

Sun and coworkers investigated degradation of phenol by a streamer corona discharge and spark discharge. They studied the effects of addition of hydrogen peroxide on the removal efficiency, and products of photochemical oxidation by ultraviolet light from the discharge plasma channel, inside and outside the plasma channel, and by the spark discharge. The results showed that the removal efficiency of phenols depends on the discharge type and additive, and that it was higher for the spark discharge than for the streamer corona discharge, and that the highest efficiency was obtained when hydrogen peroxide was added to and spark discharge. The authors identified main intermediate products produced by the spark discharge as hydroquinone, pyrocatechol, andbenzoquinone, and showed that these intermediate products disappeared with the prolongation of treatment time. $^{54}$

$\mathrm{Wu}$ and colleagues used an undivided electrolytic reactor with a beta- $\mathrm{PbO}_{2}$ anode containing fluorine resin in the process of partial electrocatalytic degradation of phenol. The authors proposed possible pathway of phenol degradation, through benzoquinone as undesirable byproduct, and developed a mathematical model. They also found optimal operating conditions in the aspect of parameters that could influence the degradation rate and pathway, such as initial $\mathrm{pH}$, current density, and temperature of the reaction. In that terms, the authors concluded acidic medium of $\mathrm{pH} \mathrm{4}$, at appropriate temperature and higher current density were the conditions that favor degradation of phenols to organic acids rather than through the $\mathrm{BQ}{ }^{55}$

In order to develop a stable heterogeneous catalyst for the oxidation by hydrogen peroxide of an aqueous solution of phenol, combining the efficiency of homogeneous processes, like Fenton, and advantages of heterogeneous catalyzed processes, Catrinescu and coworkers used specially prepared catalyst using a cation doping technique, in the form of Fe-exchanged Al-pillared beidellite. The authors pointed that they chose beidellite as a catalyst, instead pillared montmorillonite, as beidellite had a more ordered distribution of pillars in the interlayer space of the clay, a higher thermal stability and significantly greater acidity. They tested parameters which could affect catalyst activity and phenol removal efficiencies such as $\mathrm{pH}$, temperature, catalyst concentration and its stability. Results showed that at $\mathrm{pH} 5.0$, the catalyst was capable of the total elimination of phenol and significant COD removal, without generating additional pollution by iron hydroxide sludges. Additionally, the catalyst was proved to be reusable for successive runs, without significant loss of activity. 
The authors also showed that the catalyst allowed to extend the range of $\mathrm{pH}$ values for which Fenton-type oxidations could occur. ${ }^{56}$

\section{CONCLUSIONS}

As we pointed that phenols are naturally present in food, and can alter the food quality, on the one hand, they are also notable pollutants of wastewater. We thus reviewed their autoxidation processes, which can be catalyzed with naturally occurrence of metal ions such as $\mathrm{Mg}, \mathrm{Ca}, \mathrm{Cu}, \mathrm{Sr}$, $\mathrm{Ba}$ and $\mathrm{Zn}$. Other naturally oxidizing agents can more chemically complex, like enzymes.

All these processes are successfully applied in AOP, both homogeneous and heterogeneous. It was showed that degradation of phenols and humic acids can be sufficiently efficient in heterogeneous AOP systems, with both UV stimulation, oxidant addition and photocatalyst, and literature data is rich with data of optimal conditions such as $\mathrm{pH}$ levels, oxidant concentrations, temperature and many other. Also, with good selection of anodic material and other specific conditions, electrochemical oxidation can be payable, while when it is about application of all types of Fenton processes, first it must consider whether it can make more damage on natural environment due to sludge disposal.

\section{REFERENCES}

1. M. Murkovic, in "Encyclopedia of Food and Health", 2016, p. 346-355; doi:10.1016/B978-0-12-384947-2.00539-0.

2. L. Pourcel, J.-M.Routaboul, V. Cheynier, L. Lepiniec and S. Debeaujon, 2017, 12, 29.

3. A. Gioxari, D. A. A Kogiannou, N. Kalogeropoulos and A. C.Kaliora, in "Encyclopedia of Food and Health", B. Caballero, P. M. Finglas and F. Toldrá (Eds.), Academic Press, 2016, p. 339-345; doi:http://dx.doi.org/10.1016/B9780-12-384947-2.00774-1.

4. C. P. Huang, C. Dong and Z. Tang, Waste Management, 1993, 13, 361.

5. J. A. Zazo, J. A. Casas, A. F. Mohedano, M. A. Gilarranz and J. J. Rodriguez, Environment Sci.Techn., 2005, 39, 9295.

6. W. Vermerris and R. Nicholson, "Phenolic Compound Biochemistry", Springer Netherlands, 2006; doi:10.1007/978-1-4020-5164-7.

7. S. T. Talcott and L. R. Howard, J. Agriculture Food Chem., 1999, 47, 2109.

8. A. Zhou and O. A. Sadik, J. Agriculture Food Chem., 2008, 56,12081 .

9. G. M. Nikolić, A. M. Veselinović, R. S.Nikolić and S. S. Mitić, Russian J. Phys. Chem., 2011, A85, 2270.

10. G. Nikolić, A. Veselinović, Ž. Mitić and S. Živanović, Acta Facultatis Medicae Naissensis, 2011, 28, 219.
11. A. M. Veselinović, R. S. Nikolić and G. M. Nikolić, Central European J. Chem., 2012, 10, 1942.

12. G. M. Nikolic, P. I. Premović and R. S. Nikolić, Spectroscopy Letters, 1998, 31, 327.

13. P. Kamau and R. B. Jordan, Inorg. Chem., 2002, 41, 3076.

14. A. V Lebedev, M. V Ivanova, A. A. Timoshin and E. K. Ruuge, Chemphyschem, 2007, 8, 1863.

15. M. Mochizuki, S. Yamazaki, K. Kano and T. Ikeda, Biochim. Biophys. Acta - Gen. Subj., 2002, 1569, 35.

16. G. T. Musie, M. Wei, B. Subramaniam and D. H. Busch, Inorg. Chem., 2001, 40, 3336.

17. N. Durán and E. Esposito, Applied Catalisys $B$ Environonment, 2000, 28, 83.

18. F. Pomar, FEBS Letter, 2002, 529, 198.

19. A. K. De, B. Chaudhuri, S. Bhattacharjee and B. K. Dutta, J. Hazard. Material, 1999, 64, 91.

20. A. H. Mahvi, A. Maleki, M Alimohamadi and A. Ghasri, Korean J. Chem. Engeenering, 2007, 24, 79.

21. R. M. Alberici and W. F. Jardim, Water Research, 1994, 28, 1845.

22. J. Chen, L. Eberlein and C. H. Langford, J. Photochem., Photobiol. A Chem., 2002, 148, 183.

23. M. Edalatmanesh, R. Dhib \& M. Mehrvar, Int. J. Chem. Kinetic, 2008, 40, 34

24. D. H. Han, S. Y. Cha and H. Y. Yang, Water Research, 2004, 38, 2782.

25. W. Najjar, S. Azabou, S. Sayadi and A. Ghorbel, Applied Catalisys B Environonment, 2007, 74, 11.

26. A. M. Veselinović, A. Lj. Bojić, M. M. Purenović, G. M. Nikolić, T. D. Anđelković, S. Dačić and D. V. Bojić, Chem. Industry, 2010, 64, 265.

27. A. Veselinović, A. Bojic, M. Purenović, D. Bojić and T. Andjelković, Zbornik Radova Tehnoloskog Fakulteta u Leskovcu, 2009, 19, 220.

28. G. S. Wang, C. H. Liao and F. J. Wu, Chemosphere, 2001, 42,379 .

29. M. Fukushima, K. Tatsumi and S. Nagao, Environmental Sci. Techn., 2001, 35, 3683.

30. C. Comninellis, Electrochim. Acta, 1994, 39, 1857.

31. S. Y. Bashtan and V. A. Bagrii, J. Water Chem. Techno., 2012, 34, 24.

32. N. Belhadj Tahar and A. Savall, J. Appl. Electrochem., 2011, 41, 983.

33. M. Panizza and G. Cerisola, Electrochim. Acta, 2003, 48, 3491.

34. M. Panizza and G. Cerisola, Electrochim. Acta, 2003, 48, 1515.

35. C. Comninellis and C. Pulgarin, J. Appl. Electrochem., 1991, 21, 703 .

36. C. Comninellis and C. Pulgarin, J. Appl. Electrochem. ,1993, 23, 108 .

37. M. Panizza, P. A. Michaud, J. Iniesta, C. Comninellis and G. Cerisola, Annali di chemica, 2002, 2, 995.

38. Y. Q. Wang, B. Gu, W. Xu and L. D. Lu, Rare Metal Material Engineering, 2007, 36, 874.

39. H. B. Lin, X. B. Liu, Z. Q. Sun and H. B. Zhang, Chem. J. Chinese Univ., 2005, 26, 1709.

40. D. T. Cestarolli and A. R. de Andrade, J. Electrochem. Soc., 2007, 154, E25.

41. K. Barbusinski, Ecology Chem. Engineering, 2009, S16, 347.

42. P. Bautista, A. F. Mohedano, J. A. Casas, J. A. Zazo and J. J. Rodriguez, J. Chem. Technol. Biotechnol., 2008, 83, 1323.

43. F. J. Rivas, F. J. Beltrán, J. Frades and P. Buxeda,Water Research, 2001, 35, 387. 
44. V. Kavitha and K. Palanivelu, Chemosphere, 2004, 55, 1235.

45. F. He and L. Lei, J. Zhejiang Univ. Sci., 2004, 5, 198.

46. O. B. Ayodele, J. K. Lim and B. H. Hameed, Chem. Engineering J., 2012, 197, 181.

47. A. Babuponnusami and K. Muthukumar, Chem. Engineering J., 2012, 183, 1.

48. A. Kahru, R. Reiman and A. Rätsep, Chemosphere, 1998, 37,301 .

49. J. Grzechulska-Damszel, M. Tomaszewska and A. W. Morawski, Desalination, 2009, 241, 118.

50. S. Esplugas, J. Giménez, S. Contreras, E. Pascual and M. Rodríguez, Water Research, 2002, 36, 1034.
51. M. Bideau, B. Claudel, L. Faure and H. Kazouan, J. Photochem., Photobiol. A Chem., 1994, 84, 57.

52. J. Sýkora, M. Pado, M. Tatarko and M. Izakovič, J. Photochem., Photobiol. A Chem., 1997, 110, 167.

53. L. Pinhedo, R. Pelegrini, R. Bertazzoli and A. J. Motheo, Appl. Catalisys B. Environment, 2005, 57, 75.

54. B. Sun, M. Sato and J. S. Clements, Environment Sci. Technol., 2000, 34, 509.

55. Z. Wu and M. Zhou, Environment Sci. Technol., 2001, 35, 2698.

56. C. Catrinescu, C. Teodosiu, M. Macoveanu, J. MieheBrendlé and R. Le Dred, Water Research, 2003, 37, 1154. 
